\title{
Using Clinical Phenotypes for Generating Dental Patient Personas
}

\author{
Jimmy Kayastha DDS*, Jay Fuehrer BS, Robert Moritz MS, Aaron Miller PhD and Amit Acharya PhD \\ Biomedical Informatics Research Center, USA
}

Submission: November 19, 2016; Published: March 27, 2017

*Corresponding author: Jimmy Kayastha, Biomedical Informatics Research Center, Marshfield Clinic Research Foundation, WI, USA, Tel: 6507966114; Email: kayastha@nova.edu

Abstract

Data driven patient personas that accurately represent the health of a patient population are critical when designing and validating the user interface of electronic health record. Our objective was to create dental patient personas from the existing clinical data within the data warehouse to accurately reflect detailed archetypical characters that represent distinct patient demographic characteristics within the Marshfield Clinic System, thus constructing a useful tool for students, researchers, and clinical information system designers.

\section{Introduction}

In order to implement effective clinical information systems design, clinically accurate patient personas are helpful. Personas are a proven design tool that, when coupled with usercentered design techniques, can ground the design process to model specific types of dental patients. Data driven patient personas would allow designers a more clear understanding of requirements for development of new clinic systems, and enable the user-interface design to be more effectively modeled. Our objective was to generate two dental patient personas as a pilot effort to represent a segment of the patient population served by our organization.

\section{Methods}

We predetermined clinical phenotypes and demographic data elements within our existing data warehouse to generate personas based on relative frequency of occurrence. For persona 1 , we identified the group of patients who received both dental and medical services within our organization. Within this cohort we identified all patients with diabetes [1] and periodontal disease [2] from November of 2002 (start date of dental services at Marshfield Clinic) to present. For persona 2, ICD- 9 diagnoses codes for dental caries (521.01 to 521.09) was used to identify patients with tooth decay from April 2010 (start date of ICD9 codes documentation for dental diseases) till date. This was followed by mining demographic information like gender, age, and insurance carriers to reflect the different clusters within each of the above population. The data sets obtained were further classified based on number of patients to determine the commonality that would represent a certain demographics within our patient population. The two dental patient personas were assigned with realistic name, personalities, motivations and a photo.

\section{Preliminary Results}

The two personas were derived from 48,413 patients who received medical as well as dental services at the Marshfield Clinic. Persona 1, Rose Petal, age 60, represented female gender with both diabetes and periodontitis and with Medicaid insurance. Rose Petal's group represented 1651 patients consisting of $51.79 \%(n=855)$ females \& $48.21 \%(n=796)$ males. The median age range was 51 to 60 , representing $26.29 \%$ of the patients with both the clinical phenotypes. Also, $65.84 \%$ $(\mathrm{n}=1087)$ within this group had Medicaid insurance. Personas 2, Charlotte Little, age 13, represented 12,211 of female patients with a diagnosis of dental caries and were on Medicaid insurance. Charlotte Little's group consisted of $54.95 \%(n=6710)$ females and $45.05 \%(n=5501)$ males who had been diagnosed at least once with dental caries. Among this group, 26.3\% ( $n=3211)$ were $<18$ years of age with $73.1 \%(n=8926)$ carrying Medicaid insurance. The unique persona demographics were driven by the majority rule.

\section{Conclusion}

Further work and co morbidities are needed to generate additional personas in order to capture the other segments within our patient population. It highlights secondary use clinical data and represents a cohort of dental patient population, which 
becomes critical when designing and validating the user interface of an electronic health record with dentists and physicians.

\section{References}

1. https://vault.it.northwestern.edu/projects/eMERGE/Public/ Phenotypes/T2D/T2DM-algorithm.pdf
2. Page RC, Eke PI (2007) Case Definitions for Use in Population-Based Surveillance of Periodontitis. J Periodontal 78(7 suppl): 1387-1399.

\section{Your next submission with Juniper Publishers} will reach you the below assets

- Quality Editorial service

- Swift Peer Review

- Reprints availability

- E-prints Service

- Manuscript Podcast for convenient understanding

- Global attainment for your research

- Manuscript accessibility in different formats

( Pdf, E-pub, Full Text, Audio)

- Unceasing customer service

Track the below URL for one-step submission https://juniperpublishers.com/online-submission.php 